\title{
Ceder e controlar o poder: estratégias presidenciais para coordenação governamental no Brasil
}

\author{
Fernanda Lima-Silva \\ Fundação Getúlio Vargas (FGV) \\ Maria Rita Loureiro \\ Fundação Getúlio Vargas (FGV)
}

Este texto examina as estratégias disponíveis ao Presidente da República para controlar a delegação de poder em áreas cedidas à base aliada, e coordenar a ação de ministros e burocracia na implementação das políticas governamentais. O trabalho empírico constituído por um estudo de caso do Ministério das Cidades nos dois governos Lula mostrou que as demandas por controle e coordenação em governos de coalizão se tornam mais cruciais em áreas prioritárias. Sem pretender generalizações, a análise desse caso pode contribuir para o aprofundamento da temática mais geral relativa à dinâmica de funcionamento do Poder Executivo no Brasil, ainda relativamente pouco estudada.

Palavras-chave: poder executivo - Brasil, delegação - controle, governabilidade, estudo de caso

[Artigo recebido em 25 de julho de 2017. Aprovado em 21 de maio de 2018.] 


\section{Ceder y controlar el poder: estrategias presidenciales en Brasil}

Este texto examina las estrategias disponibles al Presidente de la República para controlar la delegación de poder en las áreas cedidas a la base aliada, y la coordinación de ministros y de la burocracia en la implementación de políticas públicas. El trabajo empíricoconstituido por un estudio de caso del Ministerio de las Ciudades en los dos gobiernos Lula mostró como demandas por control y coordinación en los gobiernos de coalición se tornan más cruciais en áreas prioritarias. Sin pretender generalizaciones, una análisis de este caso puede contribuir para el aprofundamento de la temática más general relativa a la dinámica de los trabajos del Poder Ejecutivo en Brasil, relativamente poco estudiada.

Palabras-clave: poder ejecutivo - Brasil, delegación - control, gobernabilidad, estudio de caso

\section{Ceding and controlling power: presidential strategies in Brazil}

This text examines the strategies available to the President of the Republic to control the delegation of power in ministries conducted by the government coalition, and to coordinate the action of ministers and bureaucracy in the implementation of government policies. The empirical work - constituted by a case study of the Ministry of Cities in the two Lula governments - showed that demands for control and coordination in coalition governments become more crucial in priority areas. Without intending to generalize, the analysis of this case can contribute to the deepening of the more general theme related to the dynamics of the Executive Power in Brazil, still relatively little studied.

Key-words: executive power - Brazil, delegation - control, governance, case study 


\section{Introdução}

Presidentes da República são, sem dúvida, os atores políticos com mais poderes institucionais no Brasil. Podem influenciar a agenda legislativa, controlar a alocação de recursos, indicar e destituir autoridades do governo e, assim, implementar a sua agenda política e atender às demandas do seu eleitorado.

Hoje já é consensual a caracterização de nosso presidencialismo como de coalizão (Abranches, 1988; PAlermo, 2000; Figueiredo; LimongI, 1998; LimongI, 2006). Amplamente utilizado pela academia e até pela imprensa, esse conceito designa um quadro político-institucional que conjuga separação de poderes com um sistema partidário fragmentado, no qual o Presidente é incentivado a formar gabinetes ministeriais multipartidários, erigidos sob uma coalizão majoritária no Congresso.

Também já há consenso na literatura sobre a questão da governabilidade do presidencialismo brasileiro. Se até os anos 1990, os estudiosos apontavam grandes dificuldades de produzir governabilidade no país, relacionando-as aos próprios traços institucionais do presidencialismo (LINZ, 1990, 1994; STEPAN; SKACH, 1993), essa interpretação foi posteriormente superada. Os novos estudos diferenciaram diversos 'presidencialismos' e apontaram para a necessidade da inclusão de outras variáveis nesse debate, chamando a atenção para as regras e os procedimentos decisórios e os poderes legislativos e constitucionais do Executivo, que podem introduzir incentivos à cooperação entre os atores e influenciar a capacidade do sistema presidencialista de erigir sistemas governáveis (SHUGART; CAREY, 1992; MAINWARING, 1993).

Assim, as divergências hoje envolvem apenas as bases em que se constrói a governabilidade. Alguns autores destacam a importância das regras constitucionais (medidas provisórias) e infraconstitucionais (regras do Regimento Interno do Congresso) que concentram poder no Executivo e no Colégio de Líderes dentro do Legislativo, facilitando ou até forçando a cooperação dos demais atores para aprovar propostas do governo (FIGUEIREDO; LIMONGI, 1998; LIMONGI, 2006). Uma segunda linha interpretativa não nega as regras que concentram poder, mas aponta que a negociação entre o Executivo e Legislativo é necessária para se alcançar a governabilidade. Ou seja, o sistema brasileiro só se torna governável mediante uma estratégia cooperativa por parte da Presidência: "o Poder Executivo, como pivô do sistema político, deve negociar a formulação e a implementação de suas iniciativas políticas, requerendo ou não tais iniciativas o respaldo parlamentar" (PALERMo, 2000 , p. 12). Como reforço do argumento de Palermo (2000), pode-se lembrar que o impeachment da Presidente Dilma Rousseff, fundado em um pretenso "crime fiscal", ocorreu, de fato, por falta de respaldo parlamentar. É essa segunda linha 
interpretativa sobre a estrutura e o funcionamento do presidencialismo brasileiro que orientará as análises deste trabalho.

Adicionalmente, é necessário indicar que, além de obter apoio no Congresso, a implementação bem-sucedida da agenda do Executivo depende também da resolução do que foi chamado "dilema dos políticos na América Latina" (GEDDES, 1994). Ao nomear pessoas indicadas pela sua base aliada para postos ministeriais ou outras posições de relevo no governo, o Presidente pode lograr maioria parlamentar, mas perder capacidade de influenciar as políticas a serem desenvolvidas nesses espaços cedidos. Afinal, como supõe a autora, os indicados teriam autonomia para expressar posições distintas das presidenciais e até mesmo dar orientação própria às políticas e às verbas disponíveis para seu ministério ${ }^{1}$.

No Brasil, tal dilema se torna ainda mais dramático por conta do multipartidarismo extremado e da realização de amplas coalizões governamentais entre partidos nem sempre da mesma base ideológica, como tem ocorrido mais frequentemente hoje ${ }^{2}$. Os presidentes brasileiros devem necessariamente presidir e coordenar a ação do gabinete ministerial, cujos órgãos são dirigidos por distintos partidos da base aliada e podem ser impactados negativamente por tal agenciamento (INÁCIO, 2006). Dessa forma, o Presidente passa a se distinguir da Presidência, já que essa se torna uma arena política, em que coexistem múltiplos interesses e ideologias (PALERMO, 2000, p. 14). Cabe destacar que, enquanto esse autor define Presidência como o conjunto dos ministérios, utilizamos o termo Presidência, no âmbito deste trabalho, referindo-se especificamente aos órgãos de assessoria direta do Presidente da República, tais como Casa Civil, Secretaria Geral da Presidência da República etc.

Em suma, considerando que o Presidente se depara com claros limites em sua capacidade de livre nomeação ministerial pela necessidade de estabelecer a coalizão - situação que pode gerar desalinhamento entre a política implementada e a agenda de governo -, é viável supor que ele lance mão de estratégias para garantir o controle da delegação e a coordenação da ação ministerial. Ainda, em relação à dinâmica de formação de coalizões, Borges e Coelho (2015) indicam que, quanto maior a heterogeneidade ideológica da coalizão, maiores serão os custos da delegação e os incentivos do Presidente para controlar os partidos aliados. Portanto,

\footnotetext{
${ }^{1}$ Como a autora não trata particularmente da temática de formação de gabinetes em governos de coalizão, isso pode ter contribuído para reforçar o viés contido em sua análise relativa ao dilema dos políticos no presidencialismo da América Latina.

2 Atualmente existem 35 partidos políticos com atuação nacional (http://www.tse.jus.br/partidos/partidospoliticos/registrados-no-tse, acesso em 15 mar. 2018). Adicionalmente, nota-se tendência de aumento do número e da diversidade ideológica dos partidos nas coalizões: os gabinetes de Fernando Henrique Cardoso foram compostos por até cinco partidos de centro ou de direita, enquanto o governo de Lula contou com uma base aliada que variou de quatro a nove partidos de esquerda, direita e centro (ZUCCO; POWER, 2009).
} 
dialogando com temas da Ciência Política e da Administração Pública, a questão mais ampla que orienta a presente pesquisa é a seguinte: como a Presidência no Brasil organiza a implementação da sua agenda de governo em áreas cedidas para a base aliada, ou seja, como ela combina estratégias de controle e de coordenação da ação dos ministros e da burocracia?

Considerando fundamental o papel atribuído à determinada política pública dentro da agenda do governo, supõe-se que a Presidência recorra a estratégias especiais de controle e de coordenação nos ministérios cedidos à coalizão, quando esses são responsáveis por políticas ou programas prioritários. Estratégias especiais são as que envolvem utilização simultânea de vários tipos de controle da delegação e de coordenação da ação ministerial, que serão especificados mais adiante no texto.

O texto que se segue está organizado em três partes. Na primeira é apresentada a discussão teórica sobre controle da delegação e coordenação da ação ministerial, permitindo que na segunda parte se indique a metodologia de pesquisa baseada em estudo de caso comparado entre momentos distintos pelos quais passou o Ministério das Cidades (2003-2010). A terceira parte está dividida em três subseções, que analisam dois momentos vividos pelo Ministério nesse período, confrontando contextos de políticas não prioritárias e prioritárias, e as estratégias de controle da delegação e de coordenação implantadas entre 2007 e 2010. Um breve resumo e algumas inferências extraídas da análise desse caso fecham o trabalho.

\section{Controle político da delegação e coordenação da ação ministerial}

Levando em consideração que o debate sobre esse tema está mais consolidado na literatura internacional, em especial na análise do presidencialismo norteamericano (MOE, 1985, 1993, 2009; MOE; WILSON, 1994) e dos sistemas parlamentaristas europeus (LAVER; SHEPSLE, 1994; THIES, 2001), esta seção retoma, ainda que brevemente, a discussão sobre os principais mecanismos de controle político disponíveis ao chefe do Executivo nesses sistemas, para em seguida focar o caso brasileiro. Antes, porém, cabe indicar que estratégias de controle político são os recursos disponíveis a diferentes atores políticos no Executivo e no Legislativo, que competem entre si para influenciar a burocracia pública e, consequentemente, a implementação das políticas públicas (HUBER; SHIPAN, 2002).

A referência inicial dessa discussão é constituída pelos trabalhos seminais de Terry Moe sobre os Estados Unidos (MOE, 1985, 1993). Para se distinguir dos estudos anteriores que explicavam o desempenho do governo pelas características pessoais do Presidente da República, Moe afirma, com base nos recursos teóricos 
trazidos pela abordagem neo-institucional, que o Presidente possui incentivos para fortalecer a institucionalização da Presidência, aumentar sua liderança e exercer maior controle sobre a burocracia, o que seria efetuado por meio de duas estratégias institucionais complementares: a politização e a centralização.

A politização - processo de nomeação de pessoas externas à burocracia pública - é, segundo Terry Moe (1985), uma estratégia de controle utilizada porque os presidentes são considerados os principais responsáveis pelo desempenho de um país, precisando, assim, de criar efetiva capacidade de governança e controlar a burocracia pelo topo. Outros autores apontam diferentes razões que levam os presidentes à politização para o controle das políticas públicas como, por exemplo, Lewis (2008), que destaca essa estratégia especialmente para a situação de governos divididos, ou seja, quando o partido do Presidente não tem maioria nas duas casas do Congresso norte-americano.

A estratégia de politização também é identificada nos sistemas parlamentaristas europeus, porém ela ocorre para evitar comportamento oportunista de um ministro mais "hostil ao chefe de governo", que pode influenciar de modo indesejado o comportamento da burocracia sob a sua jurisdição. Thies (2001) demonstra que a nomeação de ministros juniores, sempre de partido diferente do partido do ministro, foi uma estratégia para monitorar os parceiros da coalizão. O argumento central do autor é que, ao delegar para ministros a responsabilidade de implementação de certas políticas públicas, o chefe do gabinete ou primeiro ministro tem duas opções: se eximir de controlar as políticas, permitindo que cada ministro atue como preferir, ou gerenciar a delegação pelo emprego de mecanismos de controle.

Já a centralização efetua-se pela concentração de funções na estrutura organizacional da Presidência para formulação de políticas públicas (RUDALEVIGE; LEWIS, 2005). Isso pode ocorrer por meio da criação de órgãos administrativos na Presidência, alterando o lócus das arenas decisórias, que são transferidas para o interior da arena presidencial para que o Presidente e seus assessores possam acompanhá-las mais de perto e efetivamente (HOWELL; LEWIS, 2002).

Outras pesquisas têm reforçado a argumentação de Moe quanto à complementaridade da utilização desses instrumentos de controle, mostrando que os presidentes historicamente se deparam com incentivos institucionais para politizar e, ao mesmo tempo, centralizar as áreas que são mais importantes em sua agenda, aumentando a capacidade gerencial da Presidência (GALVIN; SHOOGAN, 2004). Dessa forma, ao invés de deixar intacta aquela estrutura, os presidentes acabam atuando para alterá-la, influenciando as escolhas disponíveis para seus sucessores. São, portanto, "agentes de mudança" da própria estrutura da Presidência (GALVIN, 2014). 
A utilização dessas estratégias de controle político no Brasil demanda especificações. Primeiramente, há uma diferenciação importante em relação aos atores do processo de delegação, ou seja, quem é o principal e quem é o agente. O chefe do Executivo no Brasil precisa coordenar a ação da burocracia, como no presidencialismo dos EUA, mas também a ação dos ministros da base aliada, que podem agir de forma não alinhada à agenda governamental, como nos sistemas parlamentaristas multipartidários da Europa.

Em segundo lugar, observa-se que a politização é prática constitutiva da estrutura administrativa de todas as democracias contemporâneas, uma vez que os cargos de alto comando são cargos políticos reservados à livre nomeação pelo governante eleito ${ }^{3}$. O que varia entre os sistemas políticos de cada país é o tamanho ou a proporção dos cargos políticos frente ao conjunto dos servidores de carreira ${ }^{4}$.

Dessa forma, a prerrogativa presidencial de livre nomeação no contexto brasileiro exige algumas observações. Como já analisado, no Brasil os membros do Legislativo têm uma "vocação executivista", ou seja, têm grande incentivo para se transferirem do Parlamento a uma posição elevada no Executivo porque, além de não perderem seus mandatos, eles podem usufruir dos reais atrativos do cargo no Executivo: controle de recursos orçamentários, poder da caneta para nomeações e outros privilégios (SAMUELS, 2003, p. 18)5.

Portanto, a livre nomeação pode ocorrer para promover a politização, entendida no sentido convencional já adotado pela literatura sobre presidencialismo, como a nomeação de pessoas de confiança do Presidente, visando reduzir a assimetria de informações e, sobretudo, transmitir a direção política e administrativa do governo para a burocracia. Mas a nomeação pode ocorrer também para construir governabilidade, quando, simultaneamente, os partidos da coalizão indicam pessoas para ocupar cargos políticos e o chefe do Executivo indica alguém de sua confiança em cargo político inferior para monitorar os parceiros da coalizão, como

\footnotetext{
${ }^{3}$ No Brasil, os cargos políticos são referidos como de direção e assessoramento (DAS). A literatura brasileira denomina tais cargos de várias formas - cargos de confiança, cargos políticos, burocracia política, cargos de livre provimento e cargos de livre nomeação. Essas denominações compartilham o entendimento de que há um segundo tipo de burocracia, além daquela dos servidores de carreira, que é constituída por nomeações de caráter discricionário e que detém, comparativamente, maior poder administrativo e capacidade de influenciar na gestão das políticas (LOPEZ, 2015, p. 11- 12).

${ }^{4}$ No Japão, o número de cargos políticos gira em torno de dezenas e, na França, em torno de centenas. Já nos Estados Unidos, esse número cresce bastante, envolvendo milhares de pessoas e, no Brasil e no México, atinge proporções enormes, de dezenas de milhares (SCHNEIDER, 1995, p. 25).

5 Mudanças institucionais recentes aumentaram o poder dos parlamentares sobre recursos orçamentários, atribuindo obrigatoriedade de execução para uma parte das emendas individuais dos parlamentares. Assim, a Emenda Constitucional no 86, de 17 de março de 2015, tornou impositiva a execução de emendas individuais no limite de 1,2\% da receita corrente líquida prevista no projeto encaminhado pelo Poder Executivo.
} 
é o caso em sistemas parlamentaristas multipartidários europeus. Cabe lembrar que FHC, por exemplo, indicou pessoas da sua confiança, os chamados "homens do Presidente", para ocuparem os cargos de secretários executivos, garantindo, assim, algum controle sobre a base aliada (LOUREIRO; ABRUCIO, 1999, p. 79).

Assim, diferenciaremos neste trabalho subtipos de politização. Ao primeiro, denominaremos de politização diretiva, e a esse último, de politização coalizadora. Tal diferenciação se justifica analiticamente, pois, além de ter impactos diversos, as nomeações com diferentes fins podem ser utilizadas concomitantemente em vários ministérios, ou ainda dentro do mesmo ministério.

Por sua vez, a centralização precisa ser igualmente especificada para a análise do caso brasileiro. Aqui, a centralização pode ocorrer de modo similar ao norteamericano, com a transferência do lócus de uma política pública para dentro da Presidência e a mudança da própria estrutura político-administrativa da arena presidencial. Como exemplo, podemos citar o caso do Segundo Governo Vargas e de sua Assessoria Econômica, com os chamados "boêmios cívicos", que trabalhavam junto ao Presidente, no próprio palácio do Catete, inclusive varando noites, para a formulação dos projetos das grandes estatais como Petrobrás, Eletrobrás etc. (LIMA, 2013). Pode-se citar também o caso do governo de Fernando Collor de Mello, em que houve a extinção de ministérios e a transferência de suas atribuições para secretarias especiais, ligadas diretamente à Presidência (INÁCIO, 2006). Por fim, a centralização ainda pode se processar de outro modo, ilustrado com o Programa de Aceleração do Crescimento (PAC), do Governo Lula: nesse caso, o Presidente selecionou uma equipe para tomar decisões dentro do Palácio do Planalto e realizar uma intensa coordenação político-administrativa das políticas prioritárias, cuja implementação permanece nos ministérios setoriais ou mesmo com governos subnacionais.

A literatura que analisa o funcionamento interno do Poder Executivo federal no Brasil tem crescido nos últimos anos. Pesquisas recentes examinam a institucionalização da Presidência no Brasil (LAMEIRÃo, 2011, 2013), outras efetuam análises sobre esse processo, por meio da comparação entre Brasil e Argentina (INÁCIO; LLANOS, 2014). E há, ainda, estudos que discutem os vínculos entre os governos de coalizão e o gerenciamento presidencial de políticas públicas (SANTOS; VIEIRA, 2013; MACÁRIO, 2013 ).

Discutindo a capacidade de planejamento governamental para a efetiva realização das metas do PAC no contexto de ampla coalizão partidária, Santos e Vieira (2013) apontam que os presidentes brasileiros se deparam com altos custos institucionais para obter um planejamento coerente e eficaz, encontrando claros desafios à implementação adequada de sua agenda de governo. Todavia, a despeito 
dos desafios, o arcabouço institucional brasileiro capacita o chefe do Executivo para coordenar a ação dos ministros e da burocracia. Assim, os presidentes tendem a utilizar estratégias de politização e centralização simultaneamente quando há maior probabilidade de oportunismo ministerial, resultante de gabinetes mais dispersos ideologicamente, mais partidarizados e mais fracionados.

Além disso, Santos e Vieira (2013, p. 16) retomam a regulamentação, como uma terceira estratégia de controle político, entendida como "a adoção de uma norma jurídica que delimita, para os gestores públicos, o conteúdo e o formato exato da implementação de uma política pública". Fenômeno identificado também nos contextos norte-americano (MCCUBBINS; SCHWARTZ, 1984) e parlamentaristas europeus (HUBER; SHIPAN, 2002), no Brasil, o uso da regulamentação tende a crescer com o aumento da autonomia das burocracias federais, ou seja, quando as leis demandam implementação interministerial ou quando a rotatividade ministerial aumenta (SANTOS; VIEIRA, 2013). Outros estudos têm notado o crescimento da tendência de centralização das decisões legislativas na Presidência, influenciado pelo tamanho dos conflitos no interior da coalizão e da competição da oposição (INÁCIO, 2006) e pelo aumento da distância ideológica entre os partidos integrantes da coalizão (BATISTA, 2013).

Confrontando essas pesquisas mais recentes com o estudo pioneiro de Barbara Geddes, é importante frisar que elas representam avanços importantes, pois enfatizam que contextos distintos de negociação e de delegação fazem diferença. Tais pesquisas têm mostrado situações mais complexas e específicas de delegação, com distintas configurações de gabinetes de coalizão, em termos de alinhamento ideológico e contextos históricos. Além disso, o dilema dos presidentes não se configura com a mera delegação de cargos no Executivo, nem pode ser compreendido apenas com a análise da composição dos gabinetes partidários, como apontado pelos autores citados.

Em suma, incorporando elementos de teorias sobre o presidencialismo norteamericano e brasileiro e o parlamentarismo multipartidário europeu e baseando-se na premissa de que a delegação se torna ainda mais problemática quando ocorre em áreas ou políticas prioritárias da agenda governamental, a pesquisa orienta-se pelo esquema analítico apresentado a seguir, para compreender o presidencialismo de coalizão brasileiro. 
Figura 1 - Esquema analítico da pesquisa

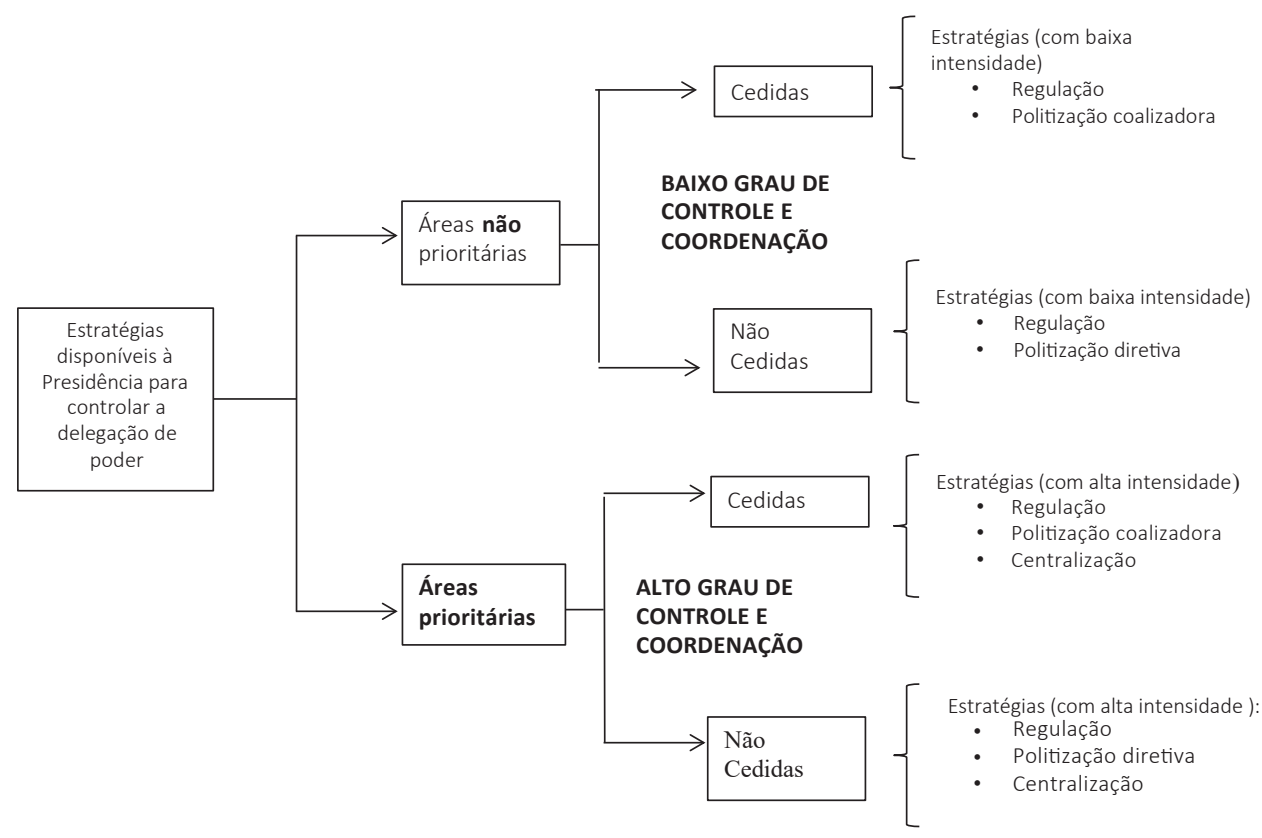

Fonte: Elaboração própria.

\section{Metodologia de pesquisa}

Do ponto de vista metodológico, a pesquisa se constitui de um estudo de caso comparado. Como a literatura indica (BoHN, 2005), esse é método mais adequado para análises orientadas por perguntas referentes ao modo de funcionamento de determinadas situações ou fenômenos (isto é, como os processos analisados ocorrem ou operam?). O caso empírico escolhido é o do Ministério das Cidades durante os dois governos Lula (2003-2010). Justifica-se a escolha desse ministério porque nele foi possível diferenciar momentos bem distintos ao longo do período examinado nos quais ocorreram diferenças nas variáveis por nós enfatizadas: atribuição de implementar políticas prioritárias na agenda governamental e cessão de cargos à base aliada.

De forma mais concreta, o MCIDADES foi comandado entre 2003 e 2005 por um ministro do PT (partido do Presidente da República), e em um segundo momento teve seu comando transferido para um ministro de outro partido, integrante da base aliada do governo, o PP (Partido Progressista). Além disso, só a partir de 2007 o ministério passou a se responsabilizar por políticas altamente prioritárias na agenda governamental. Essa multiplicidade de momentos ou tempos fez com que o MCIDADES se tornasse um lócus privilegiado para confrontar as estratégias de 
controle político da delegação presidencial e as formas específicas de coordenação administrativa das políticas prioritárias frente às não prioritárias dentro de um mesmo governo. Assim, os casos a serem aqui comparados referem-se a dois momentos distintos pelos quais o MCIDADES passou ao longo do Governo Lula: configurando-se como caso 1, o MCIDADES enquanto encarregado de políticas de baixa prioridade (2003-2006); e como caso 2, o MCIDADES após assumir atribuições relativas a políticas de alta prioridade na agenda governamental (2007-2010).

Com relação à definição de cargos políticos, cabe identificar que a literatura brasileira é marcada por duas interpretações: para a primeira, o espaço de livre provimento é amplo e indevidamente politizado, prejudicando a capacidade governamental de planejar e implementar políticas ${ }^{6}$; para a segunda, as nomeações discricionárias podem atrair quadros novos e de boa qualidade à alta burocracia, promovendo inovação e aumento da eficiência na ação governamental (LOPEZ, 2015). Nesta pesquisa, assumimos que os cargos políticos de livre nomeação podem atender a diferentes finalidades: para atender a demandas clientelistas, de interesse da base aliada; para gerar eficiência na gestão; ou, ainda, para dar direção política aos órgãos governamentais. A presente análise se concentra nos cargos que são orientados para fins diretivos e de atendimento à coalizão, vistos como estratégias de controle da delegação de poder e de coordenação governamental.

Os dados levantados foram recolhidos em fontes primárias e secundárias, constituindo-se de documentos oficiais e atos normativos de criação e atuação do MCIDADES, bem como informações de outras pesquisas, matérias de jornais, revistas e sites da internet. Também foram realizadas entrevistas semiestruturadas (ver roteiro no anexo) com quinze pessoas, entre novembro de 2013 e janeiro de 2014: sete funcionários que ocuparam cargos políticos no MCIDADES, servidores de carreira que também assumiram cargos políticos vinculados com a política habitacional na Casa Civil, Ministério do Planejamento, Orçamento e Gestão (MPOG), Ministério da Fazenda (MF) e Caixa Econômica Federal (CAIXA), dois consultores do MCIDADES e especialistas em assuntos habitacionais. A escolha desses entrevistados se pautou pela consideração de que eles eram atores-chave dos processos em estudo porque participaram, em posição central, das discussões e mesmo de decisões relativas à implementação de políticas do MCIDADES nos diferentes momentos analisados.

\footnotetext{
${ }^{6}$ Essa literatura, como o texto citado de Barbara Geddes, caracteriza o insulamento burocrático como condição necessária para diminuir a influência "política" na condução das políticas públicas.
} 


\section{Estratégias diferenciais de controle da delegação e de coordenação da ação ministerial}

\section{1) A institucionalização do Ministério das Cidades: politização diretiva e coalizadora (2003-2006)}

A criação do MCIDADES, em janeiro de 2003, no início do Primeiro Governo Lula, representou a concretização de antiga demanda de movimentos urbanos e grupos vinculados ao Projeto Moradia do Instituto Cidadania, que haviam elaborado as propostas do programa de governo do PT para essa área. A criação do ministério visava concentrar a política urbana em um único órgão, diminuindo a fragmentação antes existente. Nesse primeiro momento, o ministério foi dirigido por Olívio Dutra, importante liderança do PT, e sua equipe era formada por militantes, sindicalistas, profissionais com experiência em governos locais e prestígio nos meios acadêmicos e forte inserção nos movimentos urbanos (MARICATO, 2012, p. 26)7. Observa-se, portanto, o uso da estratégia de politização diretiva para garantir a direção política da atuação dessa recém-criada instituição.

Contudo, em 2005, essa equipe foi parcialmente desmontada. Frente à crise política que experimentou o Governo Lula com as denúncias do chamado "mensalão" e à necessidade de reconfiguração do gabinete ministerial para enfrentá-la, o posto de ministro foi cedido para o Partido Progressista (PP), que passou a compor a base aliada do governo e que indicou Marcio Fortes para Ministro. Filiado ao PP, Fortes possuía experiência na administração federal, mas era novato na área urbana. Essa troca iniciou um ciclo de incerteza sobre a continuidade da política urbana então em processo de elaboração e gerou desligamentos de parte da equipe do ministro Dutra.

Entretanto, mesmo com a nomeação de Fortes para garantir governabilidade, o Presidente Lula procurou controlar a delegação por meio de acordo com o novo ministro, para que ele mantivesse até o final do primeiro mandato e com autonomia, os indicados pelo PT na direção das quatro secretarias do ministério: SNH, SNSA, Semob e SNPU. Observa-se, então, a emergência da politização coalizadora no MCIDADES. Assim, a "nomeação para governabilidade" no gabinete ministerial coexistiu com a manutenção de pessoas de confiança do Presidente nos cargos de direção dessas secretarias. Além disso, Inês Magalhães, também do PT, substituiu

\footnotetext{
${ }^{7}$ Nesse grupo estão: Jorge Hereda, na Secretaria Nacional de Habitação (SNH) e depois CAIXA; Inês Magalhães, no Departamento de Urbanização de Assentamentos Precários (Duap) e na SNH; Raquel Rolnik, na Secretaria Nacional de Programas Urbanos (SNPU); José Carlos Xavier, na Secretaria Nacional de Mobilidade Urbana (Semob); Abelardo de Oliveira Filho, na Secretaria Nacional de Saneamento Ambiental (SNSA); e Ermínia Maricato, Secretária Executiva.
} 
Jorge Hereda na Secretaria Nacional de Habitação (SHN), quando esse foi para a CAIXA. Na verdade, como se indicará adiante, essa mudança acabou por estreitar os vínculos entre o MCIDADES e a CAIXA, instituição de suma importância para a política habitacional.

Por outro lado, Márcio Fortes indicou novos dirigentes com perfil distinto daqueles que conduziram o ministério em seus anos iniciais. A equipe nomeada para a Secretaria-Executiva e para o Gabinete do Ministro não possuía experiência na área, gerando perda de capacidade técnica e de coordenação interna.

Todavia, contradizendo as expectativas, os entrevistados apontaram que a equipe de Fortes não tentou implementar uma agenda própria e distinta da presidencial. Ao contrário, deu continuidade às políticas então em curso, conduzidas a partir daquele momento principalmente pelos secretários setoriais. Os relatos tampouco apontaram para a emergência da estratégia de centralização ou para o uso elevado da regulamentação para reduzir a influência indesejada de parceiros da coalizão ou controlar a burocracia. Isso porque as ações do ministério não tinham importância na agenda governamental, como indica um funcionário de alto escalão do MCIDADES:

Ninguém dava muita bola para o SNHIS [Sistema Nacional de Habitação de Interesse Social], afinal esse e outros programas não tinham muitos recursos. Ninguém os acompanhava a não ser o pessoal de Assuntos Federativos (por conta das emendas).

Na verdade, o MCIDADES, até 2006, não contou com um fluxo regular e significativo de recursos. Além de ter seus recursos orçamentários afetados por contingenciamentos, houve também restrições de financiamento para o FGTS, dificultando a execução e o planejamento de médio-longo prazo de suas ações. Em 2003, o MCIDADES teve um contingenciamento da ordem de $85 \%$ e, em 2004 , de $62,5 \%$, sendo o ministério da área social mais atingido (MUGNATO, 2004). A partir de 2005, houve melhora orçamentária com dotação planejada de mais de $\mathrm{R} \$ 10$ bilhões de reais, o que representava o maior orçamento anual para financiamento habitacional desde a década de 1980 (MARICATO, 2005). Mesmo assim, as atividades do ministério permaneciam fora das prioridades do governo e sujeitas a contingenciamentos.

Diante disso, nos primeiros quatro anos de sua existência, o MCIDADES se concentrou na consolidação institucional do órgão e na elaboração de normas e planejamento para os setores, processos que não implicavam gastos orçamentários significativos. Dentre as iniciativas institucionais desse período, sistematizadas no Quadro 1, destacam-se as seguintes: a Política Nacional de Habitação (PNH), as 
alterações no marco regulatório para viabilizar a construção de moradias para a classe média, a criação do Conselho das Cidades, a criação do Sistema Nacional de Habitação de Interesse Social (SNHIS) e a formulação do Plano Nacional de Habitação (PlanHab). Houve também o lançamento do programa de regularização fundiária e a elaboração da Lei do Consórcio Público, além do debate das políticas nacionais de mobilidade urbana e saneamento ambiental.

Quadro 1 - Iniciativas institucionais do Ministério das Cidades por secretaria (2003-2006)

\begin{tabular}{|c|c|c|c|c|}
\hline & 2003 & 2004 & 2005 & 2006 \\
\hline SNH & & $\begin{array}{l}\text { PNH e Conselho } \\
\text { das Cidades } \\
\text { Aperfeiçoamento } \\
\text { do marco } \\
\text { regulatório (Lei } \\
\text { 10.931) }\end{array}$ & SNHIS e FNHIS & PlanHab \\
\hline SNSA & & & $\begin{array}{l}\text { Lei de Consórcios } \\
\text { Públicos }\end{array}$ & \\
\hline SNPU & $\begin{array}{l}\text { Programa } \\
\text { Papel Passado } \\
\text { (regularização } \\
\text { fundiária) }\end{array}$ & & $\begin{array}{l}\text { Campanha } \\
\text { Nacional } \\
\text { "Plano Diretor } \\
\text { Participativo" }\end{array}$ & \\
\hline Semob & & $\begin{array}{l}\text { Debate sobre } \\
\text { Política Nacional } \\
\text { de Mobilidade } \\
\text { Urbana e } \\
\text { Saneamento } \\
\text { Ambiental }\end{array}$ & & \\
\hline
\end{tabular}

Fonte: Elaboração própria com base nos relatórios anuais de avaliação do PPA.

Além da importância em si dessa tarefa de construção institucional, esse processo teve outro impacto relevante: permitiu a capacitação da equipe técnica do MCIDADES, o que mostrou ser fator decisivo para sua posterior atuação nos programas do PAC, carro-chefe do Segundo Governo Lula. Segundo entrevistados, a elaboração, por exemplo, do PlanHab - que representou a retomada, depois de décadas, do planejamento do setor habitacional no Brasil - foi importante momento de capacitação para a equipe da SNH, porque exigiu numerosos estudos, diagnósticos e projeções de demanda por habitação para a população de baixa renda, além de análises de temas como a precificação dos produtos, cálculos de necessidade de subsídios etc. 
No contexto político-institucional de baixa prioridade na agenda governamental, o MCIDADES não foi objeto de estratégias especiais de controle da delegação e de coordenação da ação ministerial, como regulamentação ou centralização. Tampouco houve iniciativas específicas de coordenação administrativa por parte da Presidência. Mesmo quando cedido a um partido aliado com notável distanciamento ideológico do PT, em 2005, não houve alteração significativa no controle desse órgão, pois, como indica um entrevistado: "havia um script mínimo que todos os partidos da base aliada com ministérios deveriam seguir, independente de sua ideologia própria".

Além disso, paralelamente à indicação de membros da base aliada para cargos diretivos (Secretaria Executiva e Chefe de Gabinete), houve o esvaziamento das atribuições de coordenação interna do Gabinete Ministerial, reduzindo sua influência sobre a burocracia setorial. Isso pode apontar para um processo menos enfatizado na literatura: a nomeação para governabilidade coexistindo com o esvaziamento do poder dos cargos cedidos. O Quadro 2 apresenta esquematicamente as estratégias de controle da delegação utilizadas pela Presidência no MCIDADES nesse período.

\section{Quadro 2 - Estratégias de controle no MCIDADES com políticas não prioritárias}

\begin{tabular}{|c|c|c|c|}
\hline \multicolumn{2}{|c|}{$\begin{array}{l}2003 \text { - 07/2005: Ministério do partido do } \\
\text { Presidente }\end{array}$} & \multicolumn{2}{|c|}{$\begin{array}{l}\text { 07/2005 - 2006: Ministério da base } \\
\text { aliada }\end{array}$} \\
\hline 2003 & 2004 & 2005 & 2006 \\
\hline \multicolumn{2}{|c|}{ POLÍTICAS NÃO-PRIORITÁRIAS } & \multicolumn{2}{|c|}{ POLÍTICAS NÃO PRIORITÁRIAS } \\
\hline \multicolumn{2}{|c|}{$\begin{array}{l}\text { Regulamentação: reduzida. Autonomia na } \\
\text { institucionalização }\end{array}$} & \multicolumn{2}{|c|}{$\begin{array}{l}\text { Regulamentação: reduzida até } \\
\text { desenho do PAC }\end{array}$} \\
\hline \multicolumn{2}{|c|}{ Politização diretiva } & \multicolumn{2}{|c|}{ Politização coalizadora } \\
\hline \multicolumn{2}{|c|}{$\begin{array}{l}\text { Coordenação administrativa: reduzida e } \\
\text { pouco sistematizada }\end{array}$} & \multicolumn{2}{|c|}{$\begin{array}{l}\text { Coordenação administrativa: } \\
\text { reduzida e pouco sistematizada }\end{array}$} \\
\hline \multicolumn{2}{|c|}{$\begin{array}{l}\text { Membros do partido presidencial em postos } \\
\text { dirigentes: Ministro, Secretaria Executiva, } \\
\text { secretarias setoriais }\end{array}$} & \multicolumn{2}{|c|}{$\begin{array}{l}\text { Ministério compartilhado: Ministro } \\
\text { (PP) e setoriais (PT). }\end{array}$} \\
\hline
\end{tabular}

Fonte: Elaboração própria.

A despeito dessa situação de restrição orçamentária e de esvaziamento das funções de direção política, do ponto de vista do Ministro Fortes e do seu partido, a ocupação do MCidades era importante, dada a capilaridade de suas políticas, pois 
a pasta gerenciava obras e verbas que atendiam diretamente aos municípios. O que representava, obviamente, um considerável recurso político com possibilidades de gerar dividendos eleitorais ${ }^{8}$. A partir do final de 2006, quando a Presidência iniciou a formulação do PAC, as estratégias de controle da delegação e coordenação da ação ministerial são adotadas, como se indicará a seguir.

\section{Emergência das políticas urbanas na agenda prioritária da Presidência}

O segundo mandato de Lula representou inflexão na política econômica adotada no primeiro, que se pautou pela manutenção do chamado tripé macroeconômico estabelecido desde o segundo Governo FHC: metas de inflação, câmbio flutuante e elevados superávits primários na área fiscal. Sem abrir mão desse tripé, o segundo governo inaugurou-se com iniciativas claras de promoção do crescimento econômico e de expansão da demanda interna. Logo de início, lançou o PAC, destinado a retomar o investimento governamental especialmente em infraestrutura, elevar as taxas de crescimento e aumentar o emprego e a renda (PAULANI, 2008; SALLUM JR; Kugelmas, 2004; GonÇALVES; FILGUEIRAS, 2007; NoVELLI, 2010).

Na verdade, o PAC pode ser entendido como um "pacote" de políticas públicas variadas, cuja implementação envolve diversos ministérios, setor privado e governos subnacionais, demandando um conjunto de ações de coordenação. Segundo Santos e Vieira (2013, p. 8-9), existem pelo menos três obstáculos na nova ambiência institucional brasileira que podem afetar a capacidade estatal de realizar as metas do PAC: (1) sua condicionalidade federativa e os possíveis problemas político-partidários passíveis de ocorrência em um presidencialismo multipartidário; (2) problemas com processos licitatórios e órgãos de controle; e (3) problemas derivados da necessidade de coordenação intragovernamental, aqui enfatizado.

A inflexão na política econômica também produziu alterações na estrutura e funcionamento do aparato governamental e das arenas decisórias das políticas públicas. Assim, a Casa Civil, que, desde a crise política enfrentada pelo governo em 2005, havia passado para o comando da então Ministra Dilma Rousseff, teve suas atribuições políticas aumentadas: além da coordenação institucional das diversas áreas de governo, passou a assumir, juntamente com o Ministério da Fazenda e do Planejamento, um papel mais destacado na gestão das políticas econômicas (LOUREIRO; SANTOS; GOMIDE, 2011). Essa tendência se fortaleceu com a necessidade de enfrentar a crise internacional de 2008, exigindo participação mais intensa do

\footnotetext{
${ }^{8}$ Desde 2004, já havia conflitos entre o PT e sua base aliada, que disputava o MCIDADES por seu potencial eleitoral. Ver lula centraliza a Reforma e tenta ACAlmar os ministros. Folha de São Paulo, 07 jan. 2004. Disponível: <http://www1.folha.uol.com.br/fsp/brasil/fc0701200402.htm>. Acesso em: 08 jan. 2014.
} 
Estado na economia e a maior mobilização de recursos públicos para a realização de investimentos.

Também na área urbana houve mudanças: seus programas tornaram-se prioritários e a Casa Civil passou a desempenhar papel de destaque na formulação e coordenação das políticas e programas do Ministério. Se vários dos projetos prioritários incluídos no PAC desde 2007 já envolviam o MCIDADES (como Saneamento e Urbanização de Assentamentos Precários), a partir da reação do governo à crise de 2008 e do lançamento de políticas anticíclicas para reaquecer a economia, isso se acentuou. Assim, foi criado, com amplo envolvimento do empresariado e protagonismo da Casa $\mathrm{Civil}^{9}$, o Programa Minha Casa Minha Vida (PMCMV), em 2009. Além disso, a decisão de sediar a Copa Mundial de Futebol em 2014 e os Jogos Olímpicos em 2016, ao exigir obras de mobilidade urbana e saneamento ambiental, levou mais ações prioritárias para dentro do MCIDADES.

A criação do PMCMV teve duplo significado: de um lado, ele representou o deslocamento das prioridades anteriores do ministério, e, de outro, a imposição de novas prioridades pela Presidência e Casa Civil. De modo mais específico, o novo programa incorporou, ainda que parcialmente, a lógica prevista para alocação de subsídios e financiamento do Plano Nacional de Habitação, mas a estratégia global desse plano foi abandonada, principalmente os eixos que buscavam garantir uma melhor inserção urbana e uma carteira diversificada de programas para atender as diferentes necessidades habitacionais existentes (KLINTOWITZ, 2015; BRASIL, 2010). Na verdade, o PMCMV implicou a transformação da política habitacional em política de cunho dominantemente econômico, orientada pelo objetivo de ativar o mercado. Como a literatura já mostrou, essa transformação já havia ocorrido no passado, com o programa do Banco Nacional de Habitação (BNH), que fracassou em seus objetivos sociais de promover moradia para população de baixa renda, ao se atrelar à lógica empresarial (AZEVEdo; ANDRADE, 1982; ARRETCHE, 1990).

Se, de um lado, houve arrefecimento da proposta de reforma urbana, de outro, o PMCMV, como parte do PAC, acabou trazendo vantagens significativas para o MCIDADES, como revela o depoimento de entrevistada, funcionária de alto escalão da SNH:

Quando se monta a governança do PAC, com a Ministra Dilma e a Miriam Belchior na SAM (Subchefia de Articulação e Monitoramento), ali nós nos transformamos efetivamente em prioridade de governo. A política e os programas habitacionais passam a fazer parte do primeiro escalão de governo. A gente (antes) não era nada, não sabia se era infraestrutura ou se

9 http://www.piniweb.com.br/construcao/habitacao/walter-torre-antecipou-plano-de-habitacao-dogoverno-129663-1.asp 
era política social, um ministério meio híbrido, porque envolve mobilidade, tem saneamento, tem habitação (grifos nossos).

O Quadro 3 permite visualizar as principais ações de cada secretaria do MCIDADES no Segundo Governo Lula, já dentro das prioridades estabelecidas pelo PAC: enquanto o PAC 1 envolveu apenas as Secretarias de Habitação e de Saneamento Ambiental, com o PAC 2 e as obras da Copa e das Olimpíadas, todas as secretarias passaram a desenvolver políticas prioritárias.

Quadro 3 - Iniciativas institucionais do MCidades por secretarias (2007-2010)

\begin{tabular}{|c|c|c|c|c|}
\hline & 2007 & 2008 & 2009 & 2010 \\
\hline SNH & $\begin{array}{l}\text { PlanHab } \\
\text { PAC-Urbanização } \\
\text { de Assentamentos } \\
\text { Precários }\end{array}$ & PlanHab & PMCMV & $\begin{array}{l}\text { PAC } 2 \text { / } \\
\text { PMCMV } 2\end{array}$ \\
\hline SNSA & $\begin{array}{l}\text { Lei } 11.445 \\
\text { (Diretrizes } \\
\text { nacionais) } \\
\text { PAC Saneamento }\end{array}$ & & & PAC 2 \\
\hline SNPU & & & $\begin{array}{l}\text { Aprovação } \\
\text { da lei de } \\
\text { regularização } \\
\text { fundiária } \\
\text { de áreas } \\
\text { ocupadas } \\
\text { (Lei PMCMV) }\end{array}$ & $\begin{array}{l}\text { PAC } 2 \text {-Áreas } \\
\text { de risco }\end{array}$ \\
\hline Semob & $\begin{array}{l}\text { Obras de } \\
\text { mobilidade urbana } \\
\text { /Copa }\end{array}$ & & $\begin{array}{l}\text { Obras de } \\
\text { mobilidade } \\
\text { urbana/ } \\
\text { Olimpíadas }\end{array}$ & \\
\hline
\end{tabular}

Fonte: Elaboração própria com base nos Relatórios Anuais de Avaliação do PPA.

Para dimensionar o impacto das políticas do PAC, incluindo PMCMV, no MCIDADES, alguns números podem ser citados. Se, em 2005, a dotação orçamentária planejada do ministério foi de R\$ 10 bilhões, em 2009, só o PMCMV contava com recursos da ordem de 34 bilhões de reais, destinados à construção de um milhão de unidades habitacionais para famílias com renda de até dez salários mínimos. No PAC2, lançado em março de 2010, foi reforçado o papel estratégico da construção civil como propulsora do desenvolvimento econômico do país, ampliando-se, para o período de 2011-2014, a carteira de projetos e os investimentos em habitação e 
em infraestrutura social e urbana. Dessa forma, no eixo PAC2/PMCMV2, estimouse o investimento de $\mathrm{R} \$ 278$ bilhões, divididos em ações de urbanização de assentamentos precários ( $R$ \$ 30,5 bilhões) e de habitação ( $R$ \$ 176 bilhões para o Sistema Brasileiro de Poupança e Empréstimo/SBPE, administrado pelo mercado e voltado à classe média e alta, e $\mathrm{R} \$ 71,7$ bilhões para o PMCMV). A meta era construir dois milhões de novas unidades habitacionais, das quais $60 \%$ seriam destinadas a famílias com renda de até $\mathrm{R} \$ 1.395,00$ (BRASIL, 2010). De acordo com um alto funcionário do MCIDADES, "em 2003, em nenhum dos nossos cenários mais otimistas, a gente teria os recursos que a gente passou a ter em 2007".

A elevação do orçamento do MCIDADES concentrou-se nas secretarias que desenvolviam políticas prioritárias. Dentre elas, destaca-se a habitacional, conduzida pela $\mathrm{SNH}$, cujo orçamento total cresceu mais de sete vezes em menos de dez anos, um valor superior ao observado nas outras secretarias: de $\mathrm{R} \$ \mathbf{7}$ bilhões em 2002 para R\$ 51,5 bilhões em junho de 2010 (MARICATO, 2012). Ressalta-se também que, no segundo mandato Lula, como a maioria dos recursos disponíveis ao MCIDADES estava vinculada ao PAC, eles não foram objeto de contingenciamentos orçamentários, mas passaram a integrar um arranjo decisório centralizado e de monitoramento intensivo, coordenado pela Casa Civil.

\section{3) Estratégias especiais de controle da delegação e coordenação da ação ministerial - Ministério das Cidades (2007-2010)}

A transformação da política urbana em prioritária no segundo Governo Lula ocorreu simultaneamente às mudanças na equipe do MCIDADES e na estratégia de controle e coordenação exercida pela Presidência sobre esse órgão. O Ministro Márcio Fortes e seu secretário executivo (ambos do PP) permaneceram, mas quase todos os secretários indicados pelo PT saíram de seus cargos. Assim, a SNSA e a Semob passaram ao comando de políticos ligadas ao PP, sem experiência na área. A SNPU foi transferida para o comando do PMDB. A visível redução da presença do partido do Presidente no MCIDADES, junto com a manutenção de Inês Magalhães na direção da SNH, demonstra que a nomeação para governabilidade nos cargos acima coexistiu com o uso da estratégia de politização coalizadora na SNH, responsável pelas políticas prioritárias, reduzindo possíveis problemas de influência indesejada do parceiro da coalizão sobre a burocracia do setor.

Adicionalmente, ocorreu uma variação da estratégia de politização, que pode ser denominada de "politização em rede"10. Essa é exemplificada com a nomeação de Jorge Hereda para a CAIXA, que passou a trabalhar de forma coordenada política

\footnotetext{
${ }^{10}$. Com relação à estruturação de relações sociais em redes e seu uso para análise na dinâmica das forças políticas, ver Marques (2000). Sobre redes de políticas públicas, ver Schneider, 2005, e Santos, 2005.
} 
e administrativamente com Inês Magalhães, sua antiga subordinada na SNH. A CAIXA é o principal agente operador do PMCMV, responsável pela aprovação das propostas, acompanhamento das obras e realização dos repasses financeiros. O posicionamento institucional desse órgão no tocante às questões de política habitacional é decisivo para o resultado da atuação da SNH, podendo favorecer ou dificultar a execução de suas políticas. Segundo palavras de um entrevistado:

Desde o começo, o objetivo do Hereda, Ermínia e Inês era ocupar a Caixa, pois o seu Vice-Presidente era ligado ao FHC e a Palocci. Afinal, a Caixa era quem fazia a habitação acontecer no Brasil, logo tomá-la era uma meta deles. Na sua segunda fase, a Ermínia perde o cargo, cargos diretivos vão sendo tomados pelo PP, o PT vai sendo ilhado, mas, ao mesmo tempo, consegue construir outras ligações externas. O Hereda vira Vice-Presidente da CAIXA e Inês se torna secretária da SNH.

Com o PAC, observou-se a combinação de estratégias de controle da delegação no MCIDADES. Além dos diferentes subtipos de politização mencionados, as estratégias de regulamentação e centralização foram bastante acionadas pela Presidência. Confrontando áreas prioritárias e não prioritárias, nota-se claramente a utilização da estratégia da centralização da formulação das políticas públicas com prioridade. A Lei no 11.124/2005, que instituiu o SNHIS - política não prioritária na agenda presidencial -, foi elaborada pelo MCIDADES sem interferência significativa do Ministério da Fazenda e demais órgãos da Presidência. Em contraste, a Lei no 11. 578/2007, que instituiu o PAC, determina em seu artigo 2 que suas ações sejam obrigatoriamente decididas pelo Comitê Gestor (CGPAC), composto pelo ministério setorial, ministérios do Planejamento, Fazenda e Casa Civil. Também especifica em seu artigo 3 ㅇ que todas as transferências obrigatórias de recursos financeiros sejam condicionadas ao cumprimento de requisitos, tais como a identificação do objeto a ser executado, das metas e do plano de aplicação dos recursos financeiros.

Com relação ao PMCMV, a utilização do controle da delegação pela regulamentação se deu de forma ainda mais acentuada. Referindo-se apenas às operações de um dos fundos desse programa, o Fundo de Arrendamento Residencial (FAR), responsável pelo financiamento da Faixa 1 (relativa aos beneficiários de renda mais baixa), os dados do website da CAIXA indicam uma enorme profusão de normas. Elas regulamentam não só as funções dos diferentes níveis de governo e as formas de transferência dos recursos do FAR, mas detalham aspectos da política, tais como as características do imóvel a ser produzido, os critérios de seleção e priorização dos beneficiários, chegando até a estabelecer regras para divulgação e publicidade do programa. Na mesma linha, Santos e 
Vieira (2013) tomam o número de palavras que cria uma determinada política pública como indicador de seu grau de regulamentação. Com base nessa diretriz, é interessante observar que a lei que cria o PMCMV contém mais de 13.000 mil palavras, em contraste, por exemplo, com a lei do SNHIS, de menor peso na agenda presidencial, que tem pouco mais de 3.000 palavras e sofreu também número bem menor de modificações. O Quadro 4 permite visualizar o nível do ativismo regulador na política prioritária do PMCMV, em confronto com o SNHIS, entre 2005 e 2011.

Quadro 4 - Regulamentação de políticas: PMCMV e SNHIS (2005/2011)

\begin{tabular}{|c|c|c|c|c|c|}
\hline \multicolumn{3}{|c|}{ PMCMV - FAR } & \multicolumn{3}{|c|}{ SNHIS } \\
\hline Norma & Data & Assunto & Norma & Data & Assunto \\
\hline Lei 11.977 & 2009 & $\begin{array}{l}\text { Dispõe sobre } \\
\text { PMCMV }\end{array}$ & $\begin{array}{l}\text { Lei } \\
11.124\end{array}$ & 2005 & $\begin{array}{l}\text { Dispõe sobre } \\
\text { SNHIS }\end{array}$ \\
\hline Lei 12.024 & 2009 & $\begin{array}{l}\text { Dispõe sobre } \\
\text { tributação }\end{array}$ & $\begin{array}{l}\text { Lei } \\
11.481\end{array}$ & 2007 & $\begin{array}{l}\text { Dá nova } \\
\text { redação à Lei } \\
11.124 / 2005\end{array}$ \\
\hline Lei 12.249 & 2010 & $\begin{array}{l}\text { Ajusta o PMCMV - } \\
\text { Lei } 11.977\end{array}$ & $\begin{array}{l}\text { Lei } \\
11.578\end{array}$ & 2008 & $\begin{array}{l}\text { Dispões sobre } \\
\text { Programa de } \\
\text { Subsídio à HIS }\end{array}$ \\
\hline Lei 12.424 & 2011 & \begin{tabular}{|l|} 
Altera a Lei \\
$11.977 / 2009$
\end{tabular} & $\begin{array}{l}\text { Lei } \\
11.888\end{array}$ & 2008 & $\begin{array}{l}\text { Altera Lei } \\
11.124 / 2005\end{array}$ \\
\hline Decreto 7.499 & 2011 & $\begin{array}{l}\text { Regulamenta Lei } \\
11.977 / 2009 \\
\end{array}$ & $\begin{array}{l}\text { Lei } \\
11.922\end{array}$ & 2009 & $\begin{array}{l}\text { Altera Lei } \\
11.124 / 2005\end{array}$ \\
\hline $\begin{array}{l}\text { Portaria } \\
\text { Interministerial } \\
\text { MTE/SDH } 02\end{array}$ & 2011 & $\begin{array}{l}\text { Enuncia regras } \\
\text { sobre o Cadastro } \\
\text { de Empregadores }\end{array}$ & & & \\
\hline $\begin{array}{l}\text { Portaria } \\
\text { Interministerial } \\
\text { MPOG/MF/ } \\
\text { MCidades } 561\end{array}$ & 2011 & $\begin{array}{l}\text { Define a } \\
\text { remuneração da } \\
\text { CAIXA }\end{array}$ & & & \\
\hline $\begin{array}{l}\text { Portaria MCidades } \\
\text { no } 325\end{array}$ & 2011 & $\begin{array}{l}\text { Dispõe sobre } \\
\text { aquisição e } \\
\text { alienação de } \\
\text { imóveis/FAR } \\
\end{array}$ & & & \\
\hline $\begin{array}{l}\text { Portaria MCidades } \\
\text { no } 368\end{array}$ & 2010 & $\begin{array}{l}\text { Dispõe sobre } \\
\text { aquisição e } \\
\text { alienação de } \\
\text { imóveis/FAR }\end{array}$ & & & \\
\hline $\begin{array}{l}\text { Portaria MCidades } \\
\text { no } 479\end{array}$ & 2010 & $\begin{array}{l}\text { Dá nova redação } \\
\text { à Portaria no } \\
\text { 93/2010 }\end{array}$ & & & \\
\hline $\begin{array}{l}\text { Portaria MCidades } \\
\text { no } 546\end{array}$ & 2011 & $\begin{array}{l}\text { Altera a Portaria } \\
\text { MCidades 59/2011 }\end{array}$ & & & \\
\hline
\end{tabular}




\begin{tabular}{|l|l|l|l|l|}
\hline $\begin{array}{l}\text { Portaria MCidades } \\
\text { no } 59\end{array}$ & 2011 & $\begin{array}{l}\text { Dispõe sobre } \\
\text { aquisição e } \\
\text { alienação de } \\
\text { imóveis/FAR }\end{array}$ & & \\
\hline $\begin{array}{l}\text { Portaria MCidades } \\
\text { no } 618\end{array}$ & 2010 & $\begin{array}{l}\text { Dispõe sobre } \\
\text { seleção de } \\
\text { entidades }\end{array}$ & & \\
\hline
\end{tabular}

Fonte: Caixa e Lei do SNHIS.

No tocante à estratégia de centralização, ela foi igualmente associada ao monitoramento intensivo das políticas prioritárias. Isso ocorreu pela formação de colegiados de gestão e monitoramento dos programas do PAC, centralizados na Casa Civil, envolvendo os ministérios setoriais e também os ministérios da Fazenda e do Planejamento. Esses colegiados acompanham de forma intensiva as políticas e interferem, quando necessário, para solucionar problemas de execução. Para isso, foi criado um aparato organizacional complexo, com diferentes funções e níveis hierárquicos.

No primeiro nível da hierarquia administrativa, há o Comitê Gestor nos ministérios, formado por técnicos que gerenciam subprogramas do PAC em cada ministério. Como o PAC engloba várias políticas públicas, os técnicos dos ministérios setoriais são distribuídos em onze "salas de situação temáticas", nas quais o cronograma das ações é detalhadamente monitorado, com atenção para os entraves no andamento das obras. Os membros das "salas de situação" possuem autonomia administrativa para solucionar os problemas identificados. Quando não são resolvidos, os problemas são encaminhados à instância superior, o Grupo Executivo do PAC (Gepac), que estabelece metas e acompanha a implementação geral das obras, atuando na resolução dos impasses de média dificuldade. $O$ Gepac é coordenado pela Casa Civil e integrado pelo Ministério do Planejamento e Ministério da Fazenda.

Acima desse nível, há o Comitê Gestor do PAC (CGPAC), composto pelos ministros da Casa Civil, Planejamento e Fazenda. O CGPAC atua sobre os problemas de maior complexidade, envolvendo nas discussões o ministro setorial da área envolvida. Contudo, se esse comitê também não conseguir solucionar o impasse, o problema é levado para a Presidência da República.

Observa-se, portanto, que a centralização da coordenação administrativa das políticas do PAC, particularmente o monitoramento intensivo, configura uma nova variação da estratégia centralizadora. Nela, a Presidência comanda o processo, ainda que possa convidar os ministérios setoriais e governos subnacionais para participar. Mesmo limitando a autonomia dos atores, a Presidência garante os recursos financeiros e o envolvimento na resolução dos problemas encontrados. 0 
Quadro 5 sintetiza o processo de controle da delegação e de coordenação da ação ministerial no MCIDADES nos diferentes momentos do período analisado.

Quadro 5 - Estratégias de controle e coordenação no MCIDADES com políticas prioritárias

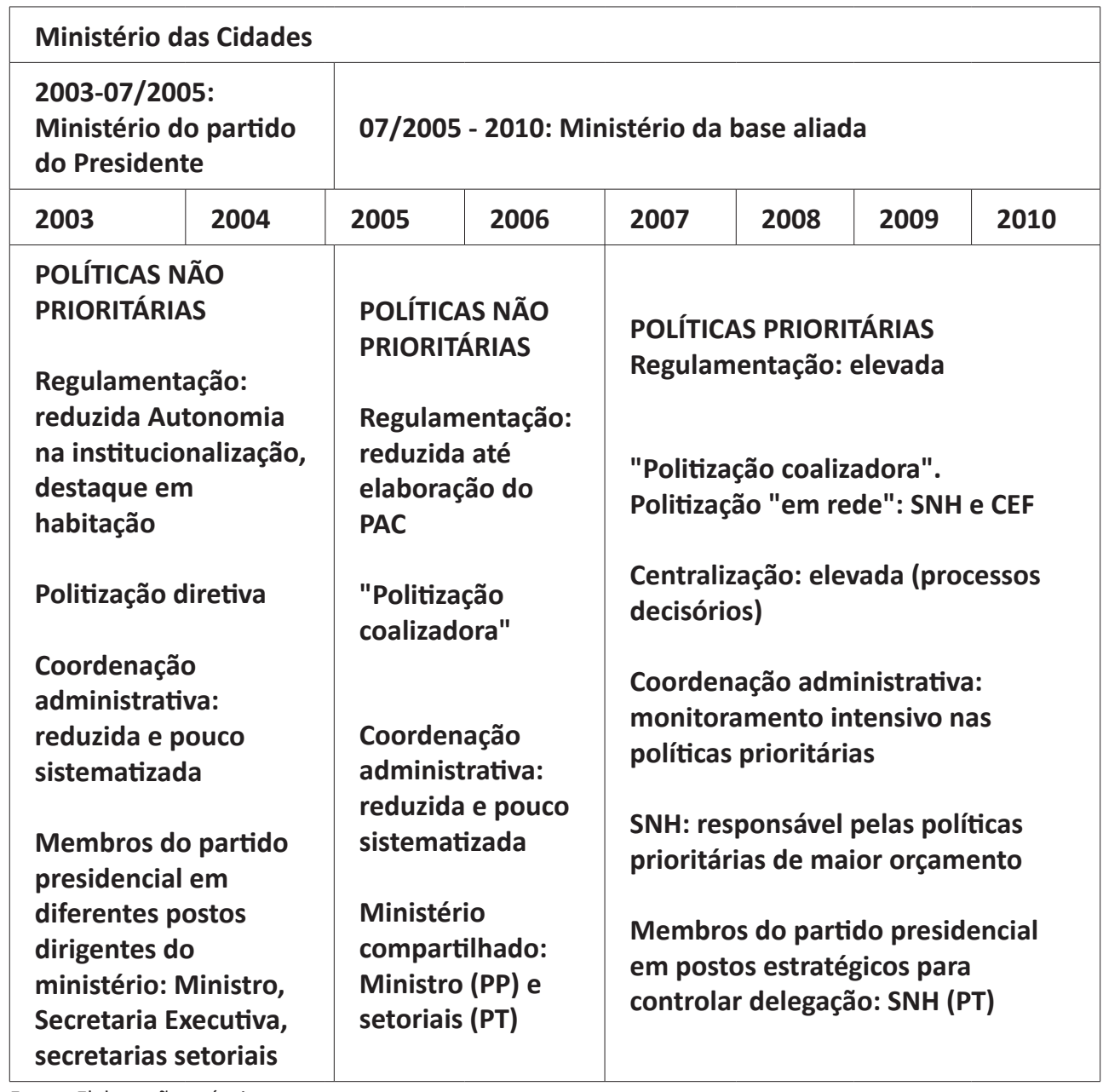

Fonte: Elaboração própria.

Em suma, as áreas do MCIDADES responsáveis por políticas que se tornaram prioritárias passaram a ter um arranjo combinado de estratégias de controle da delegação: politização, centralização e regulamentação, além de processos administrativos de monitoramento intensivo, o que não ocorreu com as demais áreas desse mesmo ministério. Portanto, a análise do controle da delegação e da coordenação da ação ministerial demanda uma análise mais refinada. Ela exige consideração, não só em termos da composição partidária e ideológica da coalizão, 
mas igualmente da agenda de prioridades de governo e de como essas são colocadas em prática no âmbito de cada órgão dentro do gabinete ministerial.

\section{Considerações finais}

Como se sabe bem, um estudo de caso não tem a pretensão de generalizar suas conclusões. Todavia, ele oferece oportunidade de aprofundar e especificar processos e conceitos necessários ao melhor entendimento de seu objeto. Assim, a análise aqui desenvolvida relativa ao controle da delegação e à coordenação da ação ministerial no presidencialismo brasileiro, que tem como referência empírica o Ministério das Cidades durante os dois governos Lula, permitiu avançar algumas conclusões que podem ser assim sistematizadas.

Em primeiro lugar, o dilema dos presidentes nos governos de coalizão, que, ao distribuírem ministérios entre partidos da base aliada, têm, ao mesmo tempo, que construir estratégias de controle da delegação (GEDDES, 1994; INÁcIO, 2006; SANTOS; VIEIRA, 2013; BATISTA, 2013), se torna ainda mais desafiante quando a delegação ocorre em áreas ou políticas prioritárias da agenda governamental. Assim, confirmando nossa hipótese, a delegação de poder em áreas prioritárias exige estratégias especiais de controle e de coordenação, combinando centralização, politização e regulamentação.

Além disso, o estudo de caso permitiu diferenciar subtipos de politização: a) diretiva; b) coalizadora; e c) politização em rede. Com o conceito de politização coalizadora, em que há a nomeação para garantir a governabilidade, observou-se ainda, no caso estudado, a estratégia de esvaziamento político dos cargos cedidos no primeiro escalão, em paralelo ao "empoderamento" de cargos estratégicos no segundo, que permanecem com membros do partido do Presidente e têm ainda seu poder reforçado por meio da estratégia de politização em rede.

Com relação especificamente à estratégia de centralização, constatou-se aqui que ela se configurou também por meio de uma estrutura complexa de coordenação administrativa com atribuições bem delimitadas e vários níveis hierárquicos para realizar o monitoramento intensivo das políticas. Mesmo que a responsabilidade direta pelas políticas tenha permanecido com os ministérios setoriais, a centralização se fez por meio de instrumentos de coordenação administrativa. Ou seja, o controle político da delegação se fez também por meio de instrumentos administrativos.

Quanto à regulamentação, reforçaram-se as referências encontradas na literatura. Além disso, indicou-se também que ela é mais detalhada e, portanto, mais extensa, quando se refere a políticas prioritárias. Em contrapartida, as políticas de 
ministérios cedidos à coalizão e que não estavam na agenda prioritária não foram objeto de estratégias especiais de controle ou de coordenação.

Por fim, nunca é demais ressaltar que só estudos mais amplos - estendidos no tempo e abrangendo diferentes governos e áreas mais ou menos estratégicas dentro de diferentes agendas presidenciais - poderão dar consistência às conclusões extraídas deste estudo de caso. De toda forma, tais conclusões são pontos de referência para futuros estudos que permitirão fortalecer o conhecimento sobre o funcionamento efetivo do Poder Executivo no Brasil e inclusive em perspectiva comparada com outros sistemas políticos.

\section{Referências bibliográficas}

ABRANCHES, S. Presidencialismo de coalizão: o dilema institucional brasileiro. Dados - Revista de Ciências Sociais, v. 31, n. 1, p. 5-34, 1988.

ARRETCHE, M. Intervenção do Estado e setor privado: o modelo brasileiro de política habitacional. Espaço e Debates, n. 31, p. 21-36, 1990.

AZevedo, S.; Andrade, L. A. G. Habitação e poder: da Fundação da Casa Popular ao Banco Nacional da Habitação. Rio de Janeiro: Zahar, 1982.

BATISTA, M. O poder no Executivo: uma análise do papel da Presidência e dos ministérios no presidencialismo de coalizão brasileiro (1995-2010). Opinião Pública, Campinas, v. 19, n. 2, p. 449-473, 2013.

BoHN, S. R. Política comparada: um mapeamento do debate entre propostas teóricas e metodologias de pesquisa alternativas. BIB. Revista Brasileira de Informação Bibliográfica em Ciências Sociais, v. 59, p. 61-80, 2005.

Borges, A.; COELHO, D. B. O preenchimento de cargos da burocracia pública federal no presidencialismo de coalizão brasileiro: análise comparada de dois ministérios - Ciência e Tecnologia e Integração Nacional. In: LOPEZ, F. G. (Org.). Cargos de confiança no presidencialismo brasileiro. Brasília: Ipea, 2015.

BRASIL. Comitê Gestor do PAC. Relatório de Lançamento do PAC 2. Brasília, 2010.

Avanços e desafios: Política Nacional de Habitação. Brasília: Ministério das Cidades, 2010.

FIgUeIREDO, A.; LIMONGI, F. Bases institucionais do presidencialismo de coalizão. Lua Nova, n. 44, p. 81-106, 1998.

Galvin, D. Presidents as agents of change. Presidential Studies Quarterly, Special Issue: Symposium on Historical Research, v. 44, p. 95-119, 2014.

Galvin, D.; Shogan, C. Presidential politicization and centralization across the modern-traditional divide. Polity, v. 36, n. 3, p. 477-504, 2004.

GedDES, B. Politician's dilemma: building state capacity in Latin America. Berkeley: University of California Press, 1994.

GonçAlves, R.; FILgueIRAS, L. A economia política do Governo Lula. Rio de Janeiro: Editora Contraponto, 2007. 
HowelL, W.; LeWIS, D. Agencies by presidential design. The Journal of Politics, v. 64, n. 4, p. 1095-1114, 2002.

HUBER, J.; SHIPAN, C. Deliberate discretion? The institutional foundations of bureaucratic autonomy. Cambridge: Cambridge University Press, 2002.

INÁCIO, M. Entre presidir e coordenar: presidência e gabinetes multipartidários no Brasil. In: Congresso Latino-AMericano de CiÊnCIA Política (Alacip), 3., 2006, Campinas. Anais... Campinas: Alacip, 4-6 set. 2006.

INÁCIO, M.; LLANOS, M. The institutional presidency from a comparative perspective: Argentina and Brazil since the 1980s. GIGA Working Papers, n. 259, p. 1-24, October 2014.

KLINTOWITZ, D. Entre a reforma urbana e a reforma imobiliária: a coordenação de interesses na política habitacional brasileira nos anos 2000. Tese (Doutorado em Administração Pública e Governo) - Escola de Administração de Empresas de São Paulo da Faculdade Getulio Vargas, 2015.

LAmeirão, C. A Casa Civil como instituição do Executivo federal. Desigualdade \& Diversidade, Dossiê Especial, p. 143-184, 2011.

A Casa Civil como estrutura de poder e controle da Presidência: gênese, trajetória e o seu desenvolvimento institucional no Governo FHC. Tese (Doutorado em Ciência Política) - Universidade Federal Fluminense, Niterói, 2013.

LAVER, M.; SHEPSLE, K. Cabinet ministers and parliamentary government. Cambridge: Cambridge University Press, 1994.

LEWIS, D. The politics of presidential appointments. Political control and bureaucratic performance. New Jersey: Princeton University Press, 2008.

LIMA, M. C. Os boêmios cívicos: a assessoria econômico-política de Vargas (19511954). Rio de Janeiro: E-Papers, 2013.

LIMONGI, F. A democracia no Brasil: presidencialismo, coalizão partidária e processo decisório. Novos Estudos - Cebrap, São Paulo, n. 76, p. 17-41, 2006.

LINZ, J. Perils of presidentialism. Journal of Democracy, Baltimore, v. 1, p. 51-69, 1990.

Presidential or parliamentary democracy: does it make a difference? In:

LINZ, J.; VAlenzuelA, A. Failure of presidential democracy. Baltimore: John Hopkins University Press, 1994. p. 3-87.

LOPEZ, F. Introdução. In: Lopez, F. G. (Org.). Cargos de confiança no presidencialismo brasileiro. Brasília: Ipea, 2015.

LOUREIRO, M. R.; ABRUCIO, F. L. Política e burocracia no presidencialismo brasileiro: o papel do Ministério da Fazenda no primeiro Governo Fernando Henrique Cardoso. Revista Brasileira de Ciências Sociais, v. 14, n. 14, p. 69-89, 1999.

LoUREIRO, M. R.; SANTOS, F.; GoMIDE, A. Democracia, arenas decisórias e política econômica no Governo Lula. Revista Brasileira de Ciências Sociais, v. 26, n. 76, p. 65-76, 2011.

MACÁRIO, Vinícius P. Coordenação governamental no presidencialismo de coalizão: O Programa de Aceleração de Crescimento e o seu impacto no Ministério dos 
Transportes. Dissertação (Mestrado em Administração Pública e Governo) - Escola de Administração de Empresas de São Paulo, Fundação Getúlio Vargas, São Paulo, 2013.

MAINWARING, S. Presidentialism, multipartism, and democracy: the difficult combination. Comparative Political Studies, v. 26, p. 198-228, 1993.

Maricato, E. A Nova Política Nacional de Habitação. O Valor, São Paulo, 24 nov. 2005.

2012.

O impasse da política urbana no Brasil. 2. ed. Petrópolis: Editora Vozes,

MARQUES, E. Redes sociais, instituições e atores políticos no governo da cidade de São Paulo. São Paulo: Fapesp, Annablume, 2003.

McCUBBINS, M.; SCHWARTZ, T. Congressional oversight overlooked: policy patrols v. fire alarms. American Journal of Political Science, v. 28, p. 165-179, 1984.

MoE, T. The revolution in presidential studies. Presidential Studies Quarterly, v. 39, n. 4, p. 701-724, 2009.

Presidents, institutions and theory. In: EdWARDS III, George; KESSEL, John; ROCKMAN, Bert (Eds.). Researching the presidency: vital questions, new approaches. Pittsburgh: University of Pittsburg Press, 1993.

. The politicized presidency. In: CHubB, John; Peterson, Paul (Eds.). The New Direction in American Politics. Washington DC: The Brookings Institution, 1985.

MOE, T.; WILSON, S. Presidents and the politics of structure. Law and Contemporary Problems, v. 57, n. 2, p. 1-44, 1994.

Mugnato, S. Ministério das Cidades é o mais afetado por cortes. Folha de São Paulo, Primeiro Caderno, p. A4, 14 fev. 2004.

NoVELLI, J. A questão da continuidade da política macroeconômica entre o governo Cardoso e Lula (1995-2006). Revista Sociologia Política, Curitiba, v. 18, n. 36, p. $227-$ 240, 2010.

PALERMO, V. Como se governa o Brasil? O debate sobre instituições políticas e gestão de governo. Dados, v. 43, n. 3, p. 521-557, 2000

PAULANI, L. Brasil Delivery - servidão financeira e estado de emergência econômico. São Paulo: Editora Boitempo, 2008.

RudAlevige, A.; LeWIS, D. Parsing the politicized presidency: centralization and politicization as presidential strategies for bureaucratic control. In: 2005 Annual Meeting of the American Political Science Association, Washington, DC, Setembro 1-4, 2005.

SALLUM JR.; B.; KUgELMAS, E. Sobre o modo Lula de governar. In: SALLUM JR., B. (Org.). Brasil e Argentina hoje: política e economia. Bauru: USC, 2004.

SAMUELS, D. Ambition, federalism, and legislative politics in Brazil; 1. ed. Cambridge: Cambridge University Press, 2003.

SANTOS, F.; VIEIRA, M. Gerenciamento presidencial de políticas públicas em governos 
de coalizão: implicações para a implementação do PAC. In: FóRUM DE ECONOMIA DA FGV, 10., 2013, São Paulo. Anais... São Paulo: Escola de Economia de São Paulo/FGV, 2013.

SANTOS, H. Perspectivas contemporâneas para a constituição de redes de políticas públicas. Civitas, Revista de Ciências Sociais, v. 5, n. 1, p. 59-68, 2005.

SCHNEIDER, B. R. A conexão da carreira: uma análise comparativa de preferências e insulamento burocrático. Revista do Serviço Público, v. 119, n. 1, p. 9-43, 1995.

SCHNEIDER, V. Redes de políticas públicas e a condução de sociedades complexas. Civitas - Revista de Ciências Sociais. Porto Alegre, v. 5, n. 1, p. 29-28, 2005.

SHUGART, M.; CAREY, J. Presidents and assemblies: constitutional design and electoral dynamics. Cambridge: Cambridge University Press, 1992.

StEPAN, A.; SKACH, C. Constitutional frameworks and democratic consolidation: parliamentarianism versus presidentialism. World Politics, v. 46, n. 1, p. 1-22, 1993.

THIES, M. Keeping tabs on partners: the logic of delegation in coalition governments. American Journal of Political Science, v. 45, n. 3, p. 580-598, 2001.

Zucco, C. J.; POWER, T. Estimating ideology of Brazilian legislative parties, 19902005: a research communication. Latin American Research Review, v. 44, n. 1, p. 218-246, 2009.

Fernanda Lima-Silva

Doutoranda em Administração Pública e Governo na Fundação Getúlio Vargas (FGV/SP). Contato: emaildefernandalima@gmail.com

\section{Maria Rita Loureiro}

Doutora em Sociologia pela Universidade de São Paulo (USP), com pós-doutorado na École des Hautes Études en Sciences Sociales, de Paris e na New York University. Atualmente é professora titular da FEA/USP e da FGV/SP. Contato: marita.loureiro@gmail.com 


\section{ANEXO I - Roteiro entrevistas}

1) Você poderia me contar sobre como é seu trabalho no dia a dia?

2) Você poderia falar sobre a criação do Sistema Nacional de Habitação? Por favor, comente sobre o papel e a influência da Presidência nesse processo.

3) Considerando sua experiência profissional e/ou acadêmica, você considera que houve mudanças na atuação do Ministério das Cidades com a troca de ministros, em 2005 (equipe, programa, objetivos)?

4) Houve alterações na relação entre o Ministério das Cidades e a Presidência com a troca de ministros, em 2005?

5) Você poderia falar sobre a criação do Plano Nacional de Habitação? Por favor, comente sobre o papel e a influência da Presidência nesse processo.

6) Você poderia comentar sobre a formulação e implementação do Programa de Aceleração de Crescimento (PAC)? Por favor, comente sobre o papel e a influência da Presidência nesse processo.

7) Você poderia comentar sobre a formulação e implementação do Programa MCMV? Por favor, comente sobre o papel e a influência da Presidência nesse processo.

8) Houve alterações no padrão da relação entre o Ministério das Cidades e a Presidência no segundo mandato, em 2007? E com o lançamento dos programas prioritários (PAC)?

9) Como o MCidades se organizou para garantir a coordenação de suas ações? Quais desafios enfrentou?

10) Por favor, comente sobre a coordenação das políticas prioritárias e não prioritárias do MCidades no Governo Lula.

11) Houve mudanças na coordenação política e administrativa do ministério durante o Governo Lula? 
RSP 